\title{
HEAD AND NECK
}

\section{Lipofilling as refinement procedure in maxillo-mandibular malformations}

\author{
II lipofilling come procedura ancillare nelle malformazioni maxillo-mandibolari

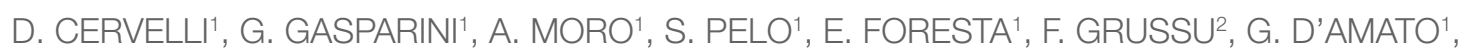 \\ P. DE ANGELIS ${ }^{1}$, G. SAPONARO 1 \\ 1 Maxillo-Facial Surgery Unit, Complesso Integrato Columbus, Università Cattolica del Sacro Cuore, Rome, Italy; \\ 2 Plastic Surgery Unit, Policlinico Universitario “A. Gemelli”, Università Cattolica del Sacro Cuore, Rome, Italy
}

\section{SUMMARY}

Maxillo-mandibular asymmetry has numerous aetiologies: congenital, traumatic, iatrogenic and post-oncologic. Patients with congenital dentofacial malformations are generally submitted to orthognathic surgery and/or additional procedures (genioplasty, alloplastic implants) with satisfactory results. However, despite achieving skeletal symmetry, noticeable facial asymmetry may persist.This study was performed in 45 patients ( 29 women and 16 men) operated between December 2012 and June 2014. All patients were affected by maxilla-mandibular asymmetry and underwent orthognatic surgery for hard tissue correction of the deformity. Residual facial alterations were then treated with lipofilling refinement proceure. In all cases good integration of the grafted fat was observed in the recipient sites. Retrospective analysis of photographic documentation showed progressive volumetric decrease for up to approximately 6 months after surgery; after that graft volume remained relatively stable. There were no significant surgical complications, either from the fat harvest site or the reconstructed site. Mild oedema and bruising were frequent during the first post-operative week. No haematomas, infections, vascular or nervous injuries were recorded. Twenty-four patients felt the need to have a second procedure. A second fat transfer was performed in 22 cases, and a third in 2 (total of 69 procedures). Based on the observations of our study, fat grafting is a simple, effective and reproducible technique, with a high satisfaction rate and few disadvantages or complications. We demonstrated that the success of lipofilling is dependent on the treated aesthetic subunits of the face. The malar and lateral cheek regions seem to be highly favourable for fat grafting, unlike the upper and lower lips subunits. Composite procedures using orthognathic surgery and autologous fat provide the surgeon with an additional, more customisable option for patients with maxillo-mandibular malformations.

KEY WORDS: Maxillo-mandibular asymmetry $\bullet$ Lipofillig $\bullet$ Orthognatic surgery

\section{RIASSUNTO}

Le asimmetrie maxillo-mandibolari riconoscono numerose eziologie: congenita, traumatica, iatrogena e post resezione oncologica. I pazienti affetti da malformazioni congenite vengono generalmente sottoposti a chirurgia ortognatica con o senza procedure aggiuntive (genioplastica, impianti alloplastici) con risultati soddisfacenti. Tuttavia, nonostante il raggiungimento della simmetria scheletrica può esitare una asimmetria residua più o meno evidente. Lo studio presentato è stato effettuato su 45 pazienti (29 femmine e 16 maschi), trattati chirurgicamente tra Dicembre 2012 e Giugno 2014. Tutti i pazienti erano affetti da asimmetria maxillo-mandibolare e sono stati sottoposti a chirurgia ortognatica per la correzione ossea della deformità. Le alterazioni residue sono state trattate con lipofilling. In tutti $i$ casi si è osservato un buon attecchimento del grasso a livello del sito ricevente. L'analisi retrospettiva della documentazione fotografica ha dimostrato un progressivo decremento dei volumi raggiunti in seguito al trattamento con lipofilling fino a sei mesi dalla procedura, dopodiché $i$ volumi sono rimasti invariati. Non sono state riportate complicanze significative sia a livello del sito donatore sia del ricevente. Un lieve edema ecchimotico è stato osservato frequentemente nella prima settimana post-operatoria, non sono stati riportati casi di ematoma, infezioni, danni nervosi o vascolari. 24 pazienti hanno avuto necessità di ulteriori applicazioni, una seconda applicazione si è resa necessaria in 22 pazienti ed una terza in 2 pazienti. (totale di 69 procedure). Sulla base dei risultati di questo studio la metodica del lipofilling si è dimostrata semplice, efficace e facilmente riproducibile, mostrando un alto indice di soddisfazione da parte dei pazienti e una scarsa incidenza di svantaggi e complicanze. Abbiamo inoltre dimostrato come il successo del riempimento con grasso autologo sia dipendente dalla subunità del viso che viene trattata. Le regioni malare e della guancia hanno mostrato i migliori risultati mentre le subunità corrispondenti al labbro inferiore e superiore hanno mostrato uno scarso attecchimento del grasso innestato, con una conseguente maggiore perdita di volume. In conclusione si può dire che le procedure composite, che prevedono l'utilizzo congiunto della correzione chirurgica delle basi scheletriche e un successivo ritocco per mezzo di innesto di grasso autologo, costituiscono una opzione addizionale e personalizzabile per i pazienti affetti da malformazioni maxillo-mandibolari.

PAROLE CHIAVE: Asimmetrie maxillo-Mandibolari $\bullet$ Lipofilling $\bullet$ Chirurgia ortognatica

Acta Otorhinolaryngol Ital 2016;36:368-372 


\section{Introduction}

Maxillo-mandibular asymmetry has numerous aetiologies: congenital, traumatic, iatrogenic and post-oncologic. Patients with congenital dentofacial malformations are generally submitted to orthognathic surgery and/or additional procedures (genioplasty, alloplastic implants) with satisfactory results. However, despite achieving skeletal symmetry, noticeable facial asymmetry may persist. This problem is the result of the asymmetrical growth of the overlying soft tissue or the effect of its accommodation after skeletal movements. Although skeletal symmetry is present, the changes of the soft tissue envelope frequently give the face a hard, more angular appearance and/or a visible asymmetry to the normal side, that compromises the final result.

The transfer of autologous fat has been performed as whole grafts since the $1890 \mathrm{~s}^{1}$ and as injectable grafts since the $1920 \mathrm{~s}^{2}$. However, it is only within the last 20 years that the popularity of autologous fat graft for facial recontouring has increased within the plastic and maxillo-facial surgery community. The wide experience recently gained with the clinical use of autologous fat transfer for facial soft tissue augmentation suggests that this procedure is the best presently available. In many ways fat is the closest we have to an ideal filler: it is readily available and inexpensive to harvest, it is autologous and therefore lacks a host immune response, it is safe and noncarcinogenic and it is acquired with a minimally invasive procedure ${ }^{3}$.

Despite the clinical optimism associated with autologous fat graft, there remains an uncertainty among practitioners regarding the viability of transferred fat ${ }^{4}$. Several methods have been suggested to improve graft survival and volume prediction: "nontraumatic" blunt cannula technique, centrifugation and immediate injection of small amounts in multiple passes ${ }^{56}$. The addition of growth factors or washing may be less meaningful ${ }^{7}$. In spite of these variable techniques for harvesting and engraftment, physician and patient satisfaction with the results of the procedure remains high, particularly in the short term ${ }^{8}$.

The aim of this retrospective study was to evaluate and optimise the role of fat grafting as adjunct refinement procedure in management of patients with maxillo-mandibular malformations.

\section{Materials and methods}

The study was performed on 45 patients ( 29 women and 16 men) operated between December 2012 and June 2014. The study was approved by the appropriate institutional review boards. Inclusion criterion was the presence of maxillo-mandibular asymmetry in patients already submitted to orthognathic surgery and/or to additional aesthetic procedures such as genioplasty or alloplastic implant placement. Excluded were patients with previous fa- cial soft tissue surgery or those who refused to participate in the study. Each subject was fully informed about the aim of the study and about the possibility that fat grafting might have to be repeated, if necessary. Informed consent was obtained at study entry. Each patient was examined preoperatively to precisely evaluate and mark any area to be treated. Preoperative and post-operative photographs were systematically obtained.

Fat harvest, preparation and reinjection were performed in a standardised fashion in accordance with Coleman's recommendations ${ }^{9}$ by the same plastic surgeon. Fat was harvested from the abdominal wall or inner knees using manual suction with a $10 \mathrm{cc}$ syringe and a $3 \mathrm{~mm}$ blunt cannula. Centrifugation was carried out at $3000 \mathrm{rpm}$ for 3 $\min$. After that, the blood/tumescent fraction was drained and the oil was removed. The resulting purified fat layer was used for grafting the maxillo-mandibular region following the principles of structural fat grafting. Multiple access sites and a fan-like pattern technique using $1.4 \mathrm{~mm}$ and $1.8 \mathrm{~mm}$ blunt cannulas were used to transfer small aliquots of fat into various depths of the soft tissue (from the dermis to the muscular fascia or muscle). A threedimensional network of tunnels was created to improve the contact between the graft and the local adipose tissue, in order to maximise its harvest. The quantity of transplanted adipose tissue was determined by attempting to obtain symmetry with the contralateral side with $30 \%$ overcorrection. Overcorrection was performed with the realisation that there will be some loss of volume over time. Postoperatively, patients were asked to come back for follow-up at weeks 2 and 4 and at months 3, 6 and 12. At each follow-up visit, surgical complications were documented and patients were photographed. Position, facial expression, focal distance and camera settings were standardised. They were also asked to rate their overall satisfaction with the post-surgical facial appearance on a five-point scale (1: poor, 2: fair, 3: good, 4: very good, 5: excellent). This scale has been utilised in and validated by several prior studies ${ }^{10-12}$.

\section{Results}

The average age of the 45 patients enrolled in the study was 29.5 years at the time of surgery. The average postoperative follow-up time was 9.7 months (range 1 to 18 months). Indications for grafts included maxillo-mandibular asymmetries after correction of congenital dentofacial malformations. Patient demographics, grafted areas, post-operative follow-up time and number of procedures are listed in Table I.

Due to its ease of access and availability, the most common donor site used was the abdominal wall (51 procedures), followed by the inner knees (18 procedures).

In all cases good integration of the grafted fat was observed in the recipient sites (Figs. 1-3). Retrospective 


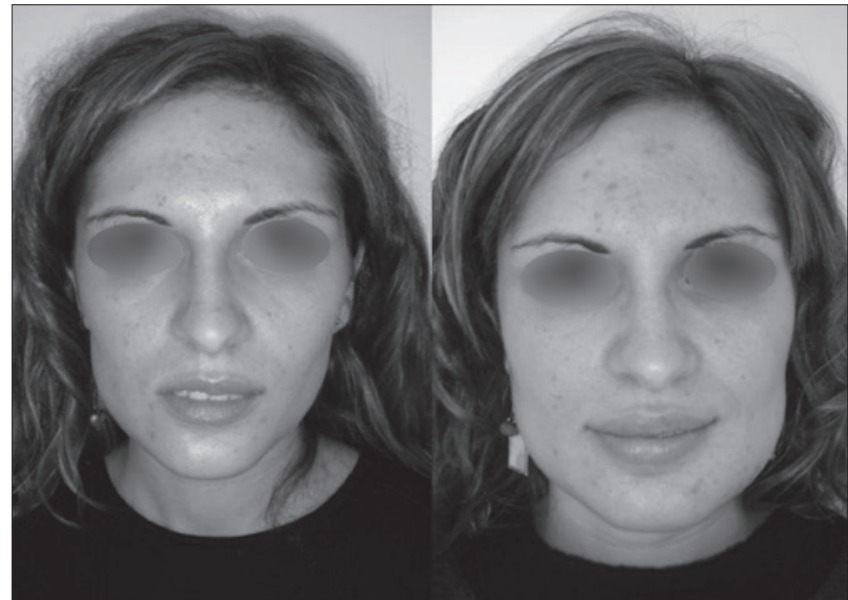

Fig. 1. A 29-year-old woman with facial asymmetry after orthognatic surgery (Patient no. 25). Postsurgical aspect after two structural grafting procedures (follow-up time: 10 months). 15 $\mathrm{ml}$ and $11 \mathrm{ml}$ of fat tissue were grafted in the left chin, lateral cheek region and in the right upper and lower lips. Note the improvement of facial symmetry.

analysis of photographic documentation showed progressive volumetric decrease for up to approximately 6 months after surgery; after that graft volume remained relatively stable.

There were no significant surgical complications, either from the fat harvest site or the reconstructed site. Mild oedema and bruising were frequent during the first postoperative week. No haematomas, infections, vascular or nervous injuries were recorded.

Twenty-four patients felt the need to have a second procedure. A second fat transfer was performed in 22 patients, and a third in 2 (total of 69 procedures).

Analysis of patient satisfaction after the last followup visit clearly demonstrated better results in the malar (mean satisfaction score [MSS]: 4.5) and lateral cheek regions (MSS: 4.2). Less satisfactory results were obtained in the chin (MSS: 3.4), nasolabial region (MSS: 3.1) and marionette folds (MSS: 2.8). The least satisfactory results were achieved in the upper (MSS: 2) and lower (MSS: 1.9) lip subunits. Satisfaction ratings for each subunit of the maxillo-mandibular region are presented in Table II.

\section{Discussion}

In facial reconstructive surgery, it is generally assumed that functional disorders should be corrected primarily. If a bone deformation is present, bone repair should be considered first. Facial volume deficiency may be corrected at a second stage. Orthognathic surgery includes all surgical procedures used to surgically treat patients affected by jaw discrepancies. The aim is to align the bony jaws into a favourable position for mastication, deglutition, respiration, and also to achieve a more desirable appearance, returning the patient to more appropriate facial proportions.
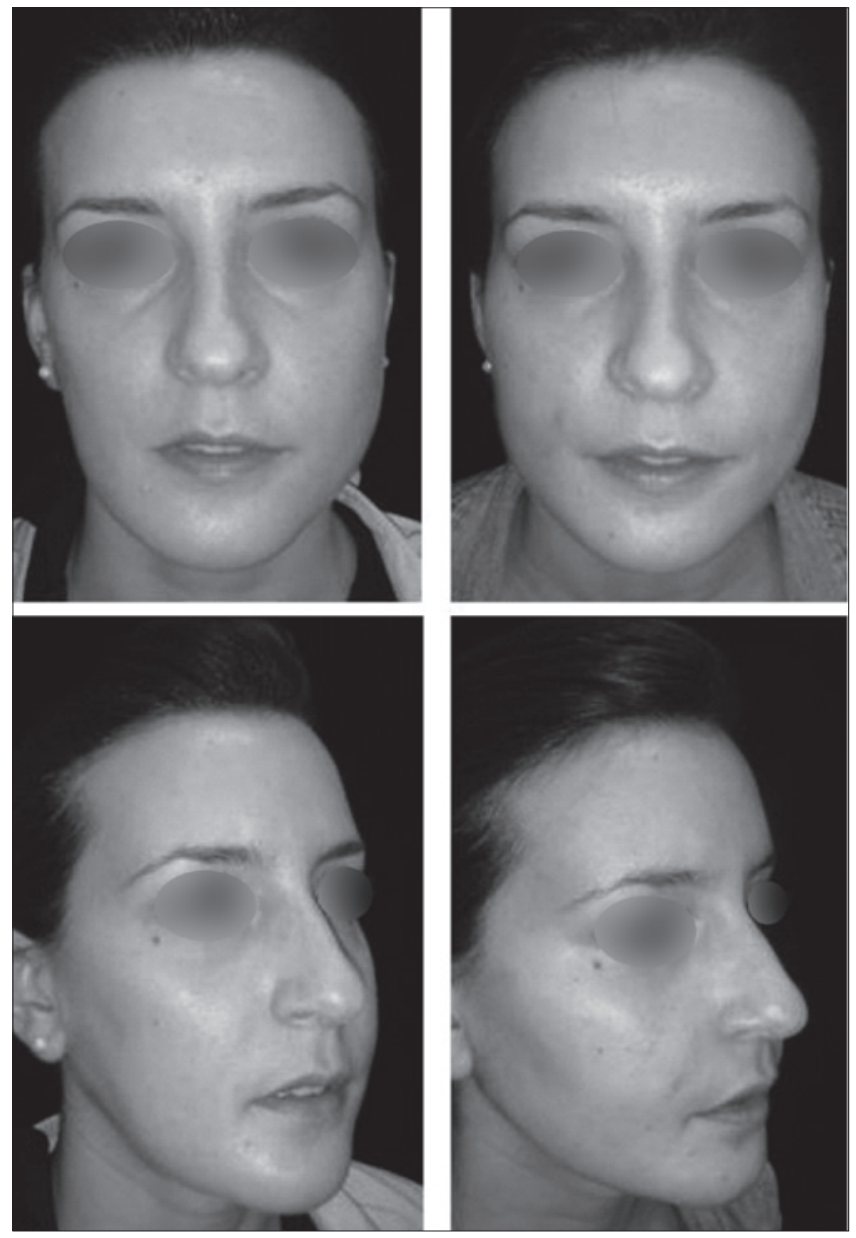

Fig. 2. (Front and lateral view). A 23-year-old woman affected by maxillo-mandibular asymmetry after orthognatic surgery (Patient no. 14). Postsurgical aspect after frontal only one structural grafting procedure (follow-up time: 13 months). $25 \mathrm{ml}$ of purified fat tissue were grafted in the right malar, lateral cheek region and mandibular angle. Note the dramatic and lasting improvement of facial symmetry.

Surgical procedures involve mobilisation of the bony jaws and their repositioning according to an accurate pre-surgical planning. Fixation is usually performed with plates and screws. The results are encouraging, but complications may be possible. Loss of sensitivity in the territories innervated by the third branch of the trigeminal nerve, malocclusion relapse, temporomandibular joint disorders, or foreign body reaction to internal rigid fixation means are the most frequent complications in orthognathic surgery. Despite the aim to recreate an appropriate facial eurhythmy, this kind of surgery may leave other cosmetic issues unaddressed, especially those related to soft tissue imbalance. Surgical options for correction include hard tissue augmentation (genioplasty, bone remodelling, autologous grafts and alloplastic materials), soft tissue augmentation (fillers, lipofilling), reduction (liposuction), cosmetic lip procedures, rhinoplasty. These procedures are preferentially performed at a later date after soft tissue 


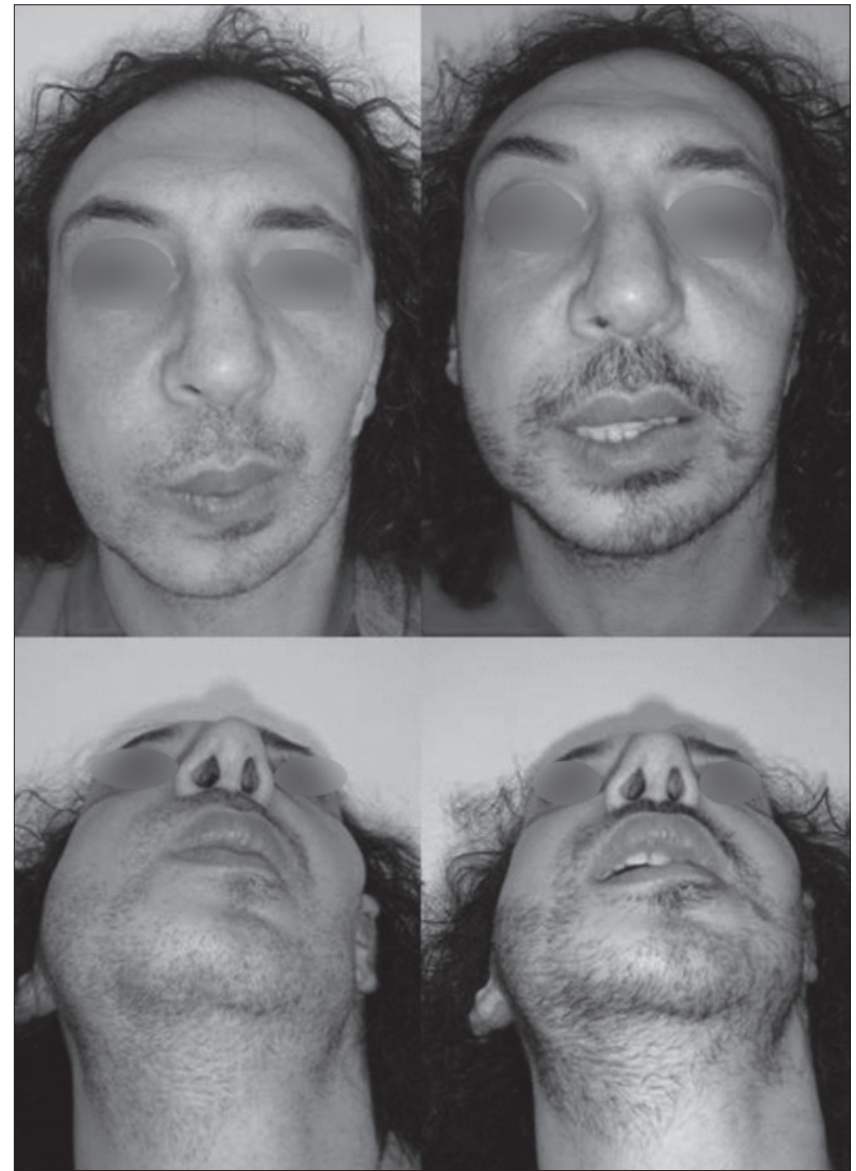

Fig. 3. (Front and inferior view). A 40-year-old man affected by Treacher-Collins syndrome with a severe facial asymmetry even after orthognatic surgery (Patient no. 40). Postsurgical aspect after two structural grafting procedures (follow-up time: 3 months). $20 \mathrm{ml}$ and $14 \mathrm{ml}$ of purified fat tissue were grafted in the left lateral cheek region, chin and nasolabial folds. Even if the postoperative result is still not satisfying, facial symmetry is improved.

oedema from orthognathic surgery has stopped, in order to achieve a more predictable outcome.

In clinical practice, procedures designed to augment soft tissues are the most commonly performed after orthognathic surgery, and fat grafting seems to be a reliable option as suggested by recent reports ${ }^{13}$ and by the results of our study. The authors believe that autologous fat can produce a more natural result for correction of maxillomandibular asymmetry. It allows the surgeon the opportunity to sequentially fine-tune and refine the final contours and volume of the soft tissue envelope, resulting in improved facial symmetry. Furthermore, improvement of skin quality of the treated region is generally observed a few months after fat grafting. We know that the face can be divided into well-defined aesthetic regions. However, these aesthetic regions can be further divided into well-accepted smaller subunits ${ }^{14}$. Numerous studies have evaluated adipocyte survival in fat grafting, but few have the clinical results according to the treated facial subu- nits. In our study, we were able to analyse the success of lipofilling in relation to the different subunits of the maxillo-mandibular region. The most satisfactory results in our study were obtained in the malar and lateral cheek regions, followed by the chin, nasolabial and marionette folds, while the poorest results were achieved in the upper and lower lip subunits.

Levels of satisfaction and percentage of results were rated as "very good" and "good" and seem to correlate with the results of Mojallal et al. ${ }^{13}$ and Fulton et al. ${ }^{15}{ }^{16}$ Similar outcomes were reported by Bertossi et al. ${ }^{17}$ in some facial recipient sites, but with the best results achieved in the lips and nasolabial folds. Similarly, Colic et al. ${ }^{18}$ found a resorption rate at 2 years in the perioral region of only $20 \%$, emphasising the importance of intramuscular fat injection. The results of our study are different. In our hands, the perioral region is an area that is difficult to correct, because of high mobility, which reduces graft taking. An overcorrection and multiple procedures are frequently necessary and intramuscular injection does not seem to prevent a high resorption rate. This is particularly true for the upper and lower lip subunits. Even with multiple fat injection procedures, our results in the chin and marionette folds are quite satisfactory, according to Fulton et al. ${ }^{15}{ }^{16}$ Differently, Eremia and Newman ${ }^{19}$ in a large series reported excellent results at 3 months, but the correction obtained was completely lost within 8 to 9 months, and repeated injections could not stabilise the results. Why are results in some anatomical regions better than in others, as shown in our study? There are no scientifically based answers, but only hypotheses which are still waiting to be experimentally confirmed. The most common hypotheses found in the literature concerns the degree of vascularisation and mobility of the recipient site and the quality of the donor-site (fibrosis, ischaemic changes, other morbidities, etc.). The studies by Mojallal et al. ${ }^{20}$ in the field of tissue engineering are of interest. Those authors stated that fat graft survival depends basically on three factors: mature adipocyte survival, differentiation of adipose-derived stem cells (preadipocytes) in mature adipocytes and the presence of extracellular matrix, absolutely necessary for the two previously mentioned factors. Adipose tissue stem cells are pluripotent and various connective tissue lines derive from them. In the authors' opinion, results are better in areas where fat tissue can be found naturally. The recipient fat tissue represents a scaffold that provides the substances to convert preadipocytes to mature adipocytes and not to other types of cells. Obviously this cannot be the case within the muscle or in contact with the fascia. This hypothesis justifies the results of our study as the best outcomes were obtained in the facial subunits where the fat was more represented (malar and lateral cheek). Another study performed by Rohrich et al. on cadavers demonstrates that subcutaneous fat of the face is partitioned into discrete anatomic compartments and that facial aging is, 
in part, characterised by how these compartments change with age, which might also be involved in some compartments retaining fat grafts better than others ${ }^{20}$.

In our series, a second fat transfer was performed in 22 patients, and a third in 2 cases. A further procedure was performed when the patient and surgeon considered the achieved result insufficient, in case of undercorrection of the defect. The reason for undercorrection could be underestimation of the required volume, high resorption of the grafted fat, or inadequate recipient site ${ }^{21}$.

Overcorrection is less common. As removal of fat without damaging the adjacent tissues is difficult, localised injection of fat should be avoided and regular distribution should be performed. In our study, no patients complained of overcorrection of the defect.

Irregularities can be observed when fat is injected too superficially or in an area with thin skin. They can be very disappointing, especially for female patients. In our series this complication was uncommon, concerning mainly the lips and mandibular profile.

The subjective evaluations of the results (preoperative and postoperative photographs) is the main limitation of this study. Despite this, our perception of the results seems to be in close relation with the level of satisfaction of patients, making the accuracy of the evaluation method relatively high.

\section{Conclusions}

Based on the observations of our study, fat grafting is a simple, effective and reproducible technique, with a high satisfaction rate and few disadvantages or complications. We demonstrated that the success of lipofilling is dependent on the treated aesthetic subunits of the face. The malar and lateral cheek regions seem to be highly favourable for fat grafting, unlike the upper and lower lips subunits. Composite procedures using orthognathic surgery and autologous fat provide the surgeon with an additional, more customisable option for patients with maxillo-mandibular malformations.

\section{References}

1 Neuber F. Fettransplantation. Zentrabl Chir 1893;22:66.

2 Miller CG. Cannula implants and review of implantation techniques in esthetic surgery. Chicago: Oak Press 1926.

3 Kaminer MS, Omura NE. Autologous fat transplantation. Arch Dermatol 2001;137:812.
4 Calabria R. Fat grafting: fact or fiction? Aesthetic Surg 2005;25:55.

5 Coleman SR. Structural fat grafts: the ideal filler? Clin Plast Surg 2001;28:111-9.

6 Coleman SR. Facial recontouring with lipostructure. Clin Plast Surg 1997;24:347-67.

7 Kaufman MR, Miller TA, Huang C, et al. Autologous fat transfer for facial recontouring: is there science behind the art? Plast Reconstr Surg 2007;119:2287-96.

8 Kaufman MR, Bradley JP, Dickinson Bm, et al. Autologous fat transfer national consensus survey: trends in techniques for harvest, preparation, application and perception of shortand long-term results. Plast Reconstr Surg 2007;119:323-31.

9 Coleman SR. Structural fat grafting: more than a permanent filler. Plast Reconstr Surg 2006;118:108S-20S.

10 Pereira LH, Sterodimas A. Composite body contouring. Aesthet Plast Surg. 2009;33:616-624.

11 Citarella FR, Sterodimas A, Condé-Green A. Endoscopically assisted limited-incision rhytidectomy: a 10 years prospective study. J Plast Reconstr Aesthet Surg 2010;63:1842-8.

12 Pereira LH, Sterodimas A. Transaxillary breast augmentation: a prospective comparison of subglandular, subfascial and submuscular implant insertion. Aesthet Plast Surg 2009;33:752-9.

13 Mojallal A, Shipkov C, Braye F, et al. Influence of the recipient site on the outcomes of fat grafting in facial reconstructive surgery. Plast Reconstr Surg 2009;124:471-83.

14 McCarthy J. Introduction to plastic surgery. In: McCarthy J, ed. Plastic Surgery. Philadelphia: Saunders 1990.

15 Fulton JE, Parastouk N. Fat grafting. Dermatol Clin 2001;19:523-30.

16 Fulton JE, Suarez M, Silverton K, et al. Small volume fat transfer. Dermatol Surg 1998;24:857-65.

17 Bertossi D, Kharouf S, D'Agostino A, et al. Facial localized cosmetic filling by multiple injections of fat stored at -30 degrees $C$ : techniques, clinical follow-up of 99 patients and histological examination of 10 patients. Ann Chir Plast Esthet 2000;45:548-555.

18 Colic MM. Lip and perioral enhancement by direct intramuscular fat autografting. Aesthetic Plast Surg 1999;23:36-40.

19 Eremia S, Newman N. Long-term follow-up after autologous fat grafting: analysis of results from 116 patients follow at least 12 months after receiving the last of minimum of two treatments. Dermatol Surg 2000;26:1150-8.

20 Rohrich RJ, Pessa JE. The fat compartments of the face: anatomy and clinical implications for cosmetic surgery. Plast Reconstr Surg 2007;119:2219-27; discussion 2228-31.

21 Mazzola RF, Cantarella G, Torretta S, et al. Autologous fat injection to face and neck: from soft tissue augmentation to regenerative medicine. Acta Otorhinolaryngol Ital 2011;31:59-69. 